\title{
Case report: a normal capnogram despite esophageal intubation
}

\section{[Étude de cas : un capnogramme normal malgré une intubation asophagienne]}

Takashi Asai MD PhD, Koh Shingu MD

Purpose: To report a case of accidental esophageal intubation which could not be detected by capnography.

Clinical features: A 43-yr-old man with osteogenic sarcoma of the mandible underwent mandibulectomy, radical neck dissection, reconstruction of the mandible and radiation therapy. He was scheduled for revision surgery to the mandible. He had a limited mouth opening and neck movement after operation and radiation. After the cuffed oropharyngeal airway (COPA ${ }^{\mathrm{TM}}$ ) was inserted, anesthesia was induced with sevoflurane, and fibreoptic nasotracheal intubation attempted, but it was impossible to insert the fibrescope into the trachea because of a deformed larynx. While equipment for tracheostomy was prepared, one last attempt was made to insert the tube blindly into the trachea. The capnograph showed apparently normal carbon dioxide waveforms, and the reservoir bag inflated and deflated regularly. However, immediately after inflation of the cuff of the tracheal tube the reservoir bag movement stopped and $\mathrm{CO}_{2}$ waveforms disappeared. Fibreoptic bronchoscopy showed that the tube was in fact in the esophagus. It was then noticed that the patient was still breathing spontaneously through the cuffed airway. The patient was awoken and tracheostomy performed. It was considered that egress of the expired gas was partially prevented by the cuffed airway, pooled in the oral cavity, aspirated down the esophagus during inspiration (likely to be due to negative intrathoracic pressure) and pushed out through the tube during expiration; inflation of the cuff prevented the gas entering the esophagus.

Conclusion: Under such exceptional circumstances, apparently normal carbon dioxide waveforms were observed despite esophageal intubation in a spontaneously breathing patient.

Objectif : Signaler un cas d'intubation œsophagienne accidentelle non détectée par capnographie.

Éléments cliniques : Un homme de 43 ans présentant un ostéosarcome de la mandibule a subi une mandibulectomie, un curage ganglionnaire cervical radical, une reconstruction de la mandibule et une radiothérapie. À la suite de la reprise chirurgicale de la mandibule et la radiothérapie prévues, on a noté une ouverture buccale et des mouvements du cou limités. Après l'insertion d'une canule bucco-pharyngée à ballonnet (COPA $\left.{ }^{\mathrm{TM}}\right)$, l'anesthésie a été induite avec du sévoflurane et l'intubation nasotrachéale fibroscopique tentée, mais impossible à cause d'une déformation du larynx. Pendant la préparation du matériel de trachéotomie, un dernier essai a été fait pour insérer la sonde à l'aveugle dans la trachée. Le capnographe a montré un oscillogramme apparemment normal du gaz carbonique et le sac-réservoir se gonflait et se dégonflait régulièrement. Mais immédiatement après le gonflement du ballonnet de la sonde trachéale, le mouvement du sac-réservoir s'est arrêté et les ondes $\mathrm{du}^{\mathrm{CO}_{2}}$ sont disparues. La fibroscopie a montré que la sonde était en fait dans l'œsophage. Notons que le patient respirait encore spontanément grâce à la canule à ballonnet. On a réveillé le patient et procédé à une trachéotomie. On a pensé que la sortie des gaz expirés avait été partiellement empêchée par la canule à ballonnet, accumulés dans la cavité buccale, aspirée dans l'œsophage pendant l'inspiration (sans doute par la pression intrathoracique négative) et refoulée au travers de la sonde pendant l'expiration; le gonflement du ballonnet a empêché l'entrée du gaz dans l'œsophage.

Conclusion : On peut observer, exceptionnellement, un oscillogramme apparemment normal du gaz carbonique malgré une intubation œsophagienne et une respiration spontanée.

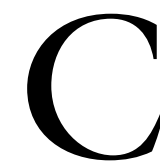

APNOGRAPHY is considered to be the most reliable method of detecting inadvertent esophageal intubation. ${ }^{1,2}$ When a tube is inserted into the esophagus, the end-tidal carbon dioxide concentration is usually either zero or much lower (up to $2 \%$ or $15 \mathrm{mmHg}$ ) than the normal exhaled gas concentration. ${ }^{3,4}$ However, a higher concentration (similar to the exhaled gas concentration) may be produced, if the stomach has been filled with carbon dioxide, such as if

From the Department of Anesthesiology, Kansai Medical University, Osaka, Japan.

Address correspondence to: Dr. Takashi Asai, Department of Anesthesiology, Kansai Medical University, 10-15 Fumizono-cho,

Moriguchi City, Osaka, 570-8507, Japan. Phone: 0081-6-6992-1001; Fax: 0081-6-6991-1301; E-mail: asait@takii.kmu.ac.jp

Accepted for publication February 15, 2001

Revision accepted August 1, 2001. 
the patient has taken a carbonated drink. ${ }^{5-7}$ Even in such a case, the maximum carbon dioxide concentration will decrease within five to six breaths ${ }^{6,7}$ so that it is unlikely that esophageal intubation will remain undetected for a prolonged period. We report a case in which apparently normal end-tidal carbon dioxide waveform continued after esophageal intubation.

\section{Case report}

A 43-yr-old man, height $170 \mathrm{~cm}$, weight $52 \mathrm{~kg}$, who had osteogenic sarcoma of the mandible, underwent tracheostomy, mandibulectomy, radical neck dissection, reconstruction of the mandible using a metal plate, and deltopectoral flap. Radiation was given to the neck after surgery. During the next 19 months, because of tissue necrosis, two operations, including a pectoralis major myocutaneous flap, were performed. The tracheostomy orifice was closed, and the mandible plate left exposed. Another three months later, the patient was scheduled for revision surgery to the mandible.

Preoperatively, the patient was conscious and was able to eat. The artificial mandibular plate limited mouth opening to $2 \mathrm{~cm}$. The view of the oropharynx was limited, and only the base of the uvula could be seen. Neck movement was markedly restricted because of operation and radiation. Tracheal intubation was predicted to be difficult because of the limited head and neck movement and mouth opening. Manual ventilation through a facemask was also predicted to be difficult, since a facemask would not fit over the mandibular defect. We planned to intubate the trachea nasally using a fibreoptic bronchoscope while the patient was breathing spontaneously under general anesthesia. We considered that the awake insertion of a cuffed oropharyngeal airway $\left(\mathrm{COPA}^{\mathrm{TM}}\right)$ (Mallinckrodt, Athlone, Ireland) was indicated, since oxygen and inhalational anesthetics can be delivered during attempts at fibrescope-aided nasotracheal intubation (Figure 1). ${ }^{8,9}$

In the operating room, after application of routine monitors, fentanyl $50 \mu \mathrm{g}$ and midazolam $3 \mathrm{mg}$, in divided doses, were injected intravenously. The patient became sedated but was responsive to verbal command. The oropharynx was anesthetized topically with $8 \%$ lidocaine spray. The cuffed oropharyngeal airway was inserted with minimum discomfort to the patient. Since adequate ventilation through the airway was obtained, anesthesia was induced by increasing the concentration of sevoflurane up to $5 \%$ in oxygen. Although the airway became partially obstructed, occasional adjustment of the position of the cuffed airway or slight head extension relieved the problem. Arterial hemoglobin oxygen saturation remained $100 \%$. Respiratory rate was $20-25$ breath $\cdot \mathrm{min}^{-1}$.

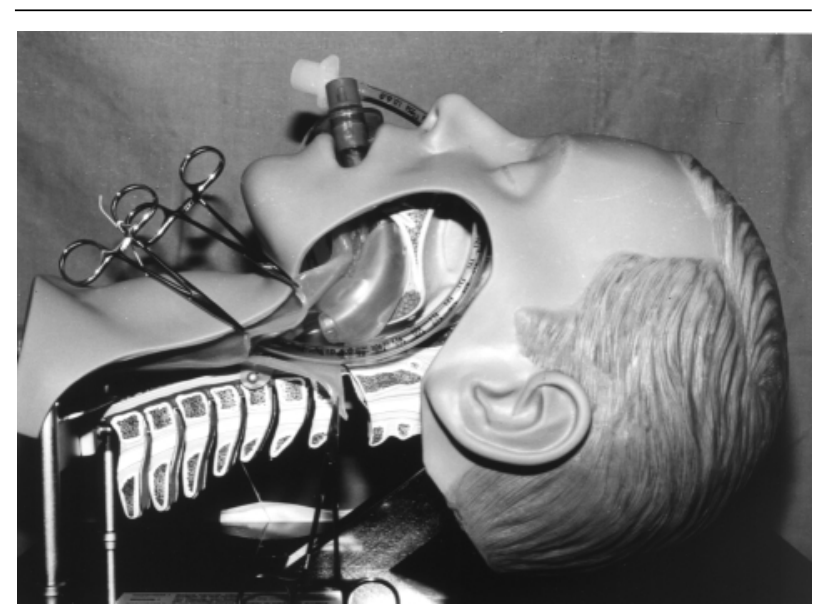

FIGURE I A fibrescope (not shown) and tracheal tube can be passed through the nose into the trachea, while oxygen and inhalational anesthetics are provided through the cuffed airway

(Reproduced from Asai $e t$ al. ${ }^{9}$ with permission from the publisher).

About ten minutes later, when the airway reflexes were judged to have been sufficiently suppressed, a fibrescope was passed through a reinforced tracheal tube (internal diameter (ID): $7.0 \mathrm{~mm}$ ) and the combination was inserted through a nostril into the oropharynx. The distal end of the cuffed airway was positioned about $2 \mathrm{~cm}$ cranial to the vocal cords. However, the device was not elevating the epiglottis, which was lying on the posterior pharyngeal wall, rendering it difficult to pass the fibrescope beyond the epiglottis. After considerable difficulty, it became possible to locate the glottis. Both the epiglottis and arytenoid cartilages were enlarged, and the latter were displaced inwardly toward the glottis, narrowing the supra-glottic region. The hypopharynx and esophagus remained open and the esophageal lumen widened during inspiration and narrowed during expiration. Because of the narrowed glottis, both the fibrescope and the tube were removed and the $7.0-\mathrm{mm}$ ID tube was replaced by a $6.0-\mathrm{mm}$ ID tube reinforced tube. Several attempts at advancing the fibrescope into the trachea failed, as the tip of the fibrescope always slipped into the esophagus.

It was decided to perform a tracheostomy after awakening the patient. Yet, before removal of the tracheal tube from the nose, one last attempt was made to insert the tube blindly into the trachea. The tube was inserted about $25 \mathrm{~cm}$, the breathing system was detached from the cuffed airway and attached to the tracheal tube while the cuffed airway was left in place. Surprisingly, the capnograph showed apparently nor- 


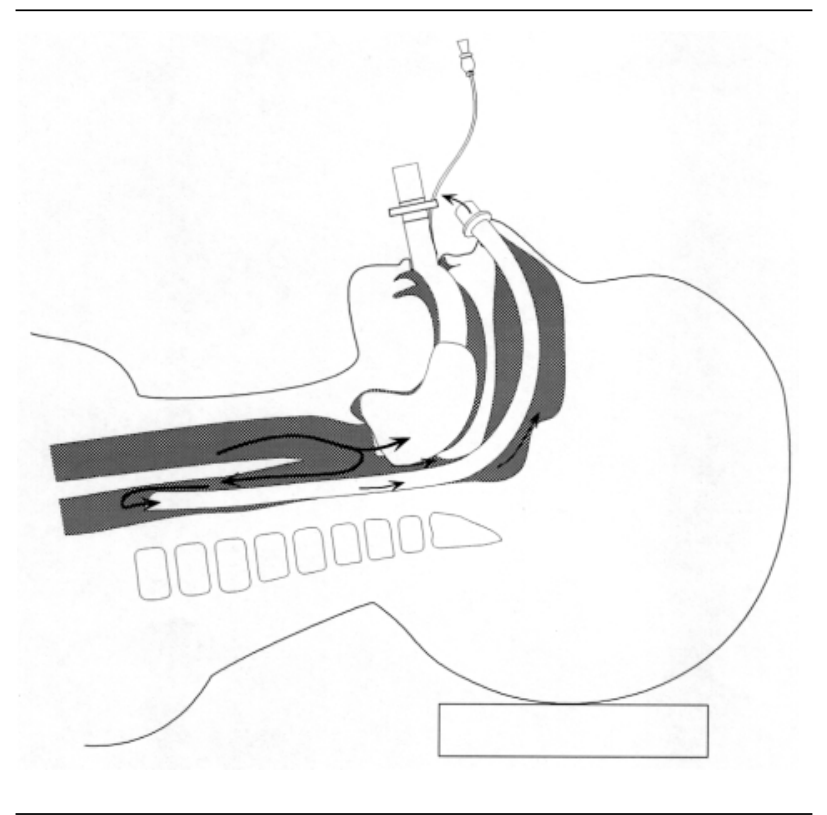

FIGURE 2 A likely explanation for the normal capnogram despite esophageal intubation in our spontaneously breathing patient. Expiration of gas was probably hampered by the cuffed oropharyngeal airway and the presence of a tracheal tube in the nose. It is possible that expired gas was pooled in the oral cavity, aspirated into the stented esophagus during inspiration and forced out through the tube during expiration; inflation of the cuff prevented gas entering the esophagus (see text for details).

mal carbon dioxide waveforms: the concentration increased and decreased regularly, synchronized with inspirations and expirations; the peak concentration ranged $38-40 \mathrm{mmHg}$ with the minimum concentration of $0-3 \mathrm{mmHg}$. The reservoir bag (connected to the tracheal tube via a breathing system) also inflated and deflated regularly, although bag movement was slight. The chest expanded adequately and auscultation of the chest indicated good air entry. During this period lasting several minutes, peak carbon dioxide concentration remained constant.

Since capnography indicated a successful tracheal intubation, the cuff of the tracheal tube was inflated. Immediately after, movement of the reservoir bag stopped and there was no longer any increase in carbon dioxide concentration. Deflation of the tracheal tube cuff produced waveforms, but this time the peak concentration was much lower (less than $10 \mathrm{mmHg}$ ). Fibreoptic bronchoscopy showed that the tube was, in fact, inserted deeply into the esophagus. It was then noticed that the patient was still breathing spontaneously through the cuffed airway. Throughout the procedure, hemoglobin oxygen saturation remained greater than $98 \%$. The patient was allowed to awaken and tracheostomy performed. The operation proceeded uneventfully thereafter.

\section{Discussion}

Although capnography is undoubtedly one of the most reliable methods to confirm tracheal intubation, ${ }^{1,2}$ apparently normal carbon dioxide waveforms could appear, even if the tube is not correctly inserted into the trachea. In one report, ${ }^{10}$ normal carbon dioxide waveforms appeared for a prolonged period, because a tracheal tube was coiled in the oropharynx and the tip of the tube was positioned above the glottis. In our case, the tracheal tube was in the esophagus. The tube was inserted down to the $25-\mathrm{cm}$ marking at the nostril. Although we did not measure the distance from the nostril to the glottis in our case, usually the distance in men is about $20 \mathrm{~cm} .{ }^{11,12}$ This indicates that the tip of the tracheal tube would have been about $5 \mathrm{~cm}$ caudal to the glottis (either in the trachea or in the esophagus). In fact, endoscopy confirmed that the tube was not coiled and inserted deeply into the esophagus.

The exact mechanisms to explain the apparently normal capnogram despite accidental esophageal intubation are not clear, but likely explanations are as follows. First, the esophagus was anatomically distorted, and remained patent, possibly because of the scarring from the previous surgery and radiotherapy. Normally the esophagus has no intrinsic structure to maintain its patency, so that when a negative pressure is applied it easily collapses and no or little gas is aspirated. This principle is utilized by an esophageal detector device, which has been shown to be reliable in detecting esophageal intubation in paralyzed patients. ${ }^{13,14}$ Our patient was breathing spontaneously and the esophagus remained open; the lumen widened during inspiration and narrowed during expiration.

Second, expiration of gas was probably hampered by the cuffed oropharyngeal airway and the presence of a tracheal tube in the nose. The cuffed airway can be used to allow oxygenation during attempts at nasotracheal intubation and while confirming the position of the tracheal tube, since the distal end of the cuffed airway is usually positioned just above the tip of the epiglottis and the device occupies the oral cavity. ${ }^{15}$ We used this technique in our patient who was breathing only through the narrow orifice of the cuffed airway and the nose during attempts at fibreoptic intubation. In addition, a tracheal tube and a fibrescope were obstructing one nasal passage. Therefore, it is possible that expired gas was pooled in the oral cavity and travelled down into the esophagus during inspiration (Figure 2). 
Carbon dioxide waveforms disappeared after inflation of the endotracheal tube cuff and waveforms reappeared (although with lower peak concentrations) after deflation of the cuff. These suggest that the expired gas entered the esophagus during inspiration (likely due to negative intrathoracic pressure), and forced gas out through the tube during expiration; inflation of the cuff prevented gas entering the esophagus.

Robinson reported, before capnography became available, exhalation of gas from a tube that was inserted into the esophagus. ${ }^{16} \mathrm{He}$ inserted a tube into the trachea and another tube into the esophagus in a patient breathing spontaneously, and found that by occluding the tracheal tube, "tidal volumes" of $50 \mathrm{~mL}$ came out of the esophageal tube. ${ }^{16}$ He stated that the patient "may be able to move the reservoir bag of the circuit and mimic normal respiration if the esophagus has been inadvertently intubated and the airway obstructed by the insertion of a throat pack." 16 This report supports our hypothesis.

Our report indicates that, under exceptional circumstances, when a patient is breathing spontaneously, apparently normal carbon dioxide waveforms, in addition to reservoir bag and chest movement, can be observed and clear lung sounds heard despite accidental esophageal intubation.

\section{References}

1 Birmingham PK, Cheney FW, Ward RJ. Esophageal intubation: a review of detection techniques. Anesth Analg 1986; 65: 886-91.

2 Clyburn P, Rosen M. Accidental oesophageal intubation. Br J Anaesth 1994; 73: 55-63.

3 Sum-Ping ST, Mehta MP, Anderton JM. A comparative study of methods of detection of esophgeal intubation. Anesth Analg 1989; 69: 627-32.

4 Linko K, Paloheimo M, Tammisto T. Capnography for detection of accidental oesophageal intubation. Acta Anaesthesiol Scand 1983; 27: 199-202.

5 Sum-Ping ST. Esophageal intubation. Anesthesia and Analgesia 1987; 66: 483.

6 Zbinden S, Schüpfer G. Detection of oesophageal intubation: the cola complication. Anaesthesia 1988; 44: 81 .

7 Sum Ping ST, Mehta MP, Symreng T. Reliability of capnography in identifying esophageal intubation with carbonated beverage on antacid in the stomach. Anesth Analg 1991; 73: 333-7.

8 Uezono S, Goto T, Nakata $\Upsilon$, Ichinose F, Niimi $\Upsilon$, Morita $S$. The cuffed oropharyngeal airway, a novel adjunct to the management of difficult airways. Anesthesiology 1998; 88: 1677-9.

9 Asai T, Matsumoto H, Shingu K. Awake insertion of the cuffed oropharyngeal airway for nasotracheal intu- bation. Anaesthesia 1999; 54: 492-3.

10 Deluty $S$, Turndorf $H$. The failure of capnography to properly assess endotracheal tube location. Anesthesiology 1993; 78: 783-4.

11 Eagle CCP. The relationship between person's height and appropriate endotracheal tube length. Anaesth Intens Care 1992; 20: 156-60.

12 Hartrey R, Kestin IG. Movement of oral and nasal tra cheal tubes as a result of changes in head and neck position. Anaesthesia 1995; 50: 682-7.

13 Wee MrK. The oesophagael detector device. Assessment of a new method to distinguish esophagea from tracheal intubation. Anaesthesia 1988; 43: 27-9.

14 Salem MR, Wafai $\Upsilon$, Baraka A, Taimorrazy B, Joseph $N J$, Nimmagadda $U$. Use of the self-inflating bulb for detecting esophageal intubation after "esophageal ven tilation". Anesth Analg 1993; 77: 1227-31.

15 Greenberg RS, Kay NH. Cuffed oropharyngeal airway (COPA) as an adjunct to fibreoptic tracheal intubation. Br J Anaesth 1999; 82: 395-8.

16 Robinson JS. Respiratory recording from the oesophagus. Br Med J 1974; 4: 225. 